\title{
Peminjaman Dan Pengembalian Buku Perpustakaan Dengan Metode Rapid Application Development Pada SMA Nusantara 1 Tangerang
}

\author{
Noer Azni Septiani ${ }^{*}$, Retno Wati ${ }^{2}$ \\ 1,2 Program Studi Sistem Informasi,Universitas Bina Sarana Informatika \\ *noer.nas@bsi.ac.id
}

\begin{abstract}
Abstrak
Rangka mendukung pendidikan nasional melalui penyediaan sumber belajar, perpustakaan harus berperan sebagai pusat belajar yang memenuhi kebutuhan siswa terutama di SMA Nusantara 1 Tangerang.Perpustakaan SMA Nusantara 1 Tangerang bertujuan meningkatkan minat baca siswa menumbuhkan bakat dan kecerdasan intelektual, spiritual dan emosional diri. Saat ini penerapan sistem peminjaman dan pengembalian buku hingga pembuatan laporan di perpustakaan SMA Nusantara 1 Tangerang masih dilakukan secara manual, sehingga dapat terjadinya kesalahan dalam proses pencatatan dan data yang dicatat pada kertas yang bisa sewaktuwaktu rusak atau hilang. Perancangan program ini dibuat agar proses peminjaman dan pengembalian buku hingga pembuatan laporan pada perpustakaan SMA Nusantara 1 Tangerang dapat dilakukan dengan efektif dan efisien, dalam pengembangan sistem informasi peminjaman dan pengembalian buku pada SMU Nusantara 1 Tangerang penulis menggunakan metode RAD, karena merupakan salah satu metode pembangunan sistem yang ditujukan untuk menyediakan pengembangan yang jauh lebih cepat dan mendapatkan menghasikan dengan kualitas yang lebih baik. Penulis mengunakan RAD selain bertujuan mempersingkat waktu biasanya jg diperlukan dalam siklus hidup pengembangan sistem tradisional antara perancangan dan penerapan suatu sistem informasi.
\end{abstract}

Kata kunci: Perpustakaan, peminjaman, pengembalian, RAD

\begin{abstract}
In order to support national education through the provision of learning resources, the library must act as a learning center that meets the needs of students, especially at SMA Nusantara 1 Tangerang. Currently, the application of the system for borrowing and managing books to making reports at the SMA Nusantara 1 Tangerang library is still done manually, so errors can occur in recording and data recorded on paper that is damaged or lost at any time. This design program is made so that the process of borrowing and developing books to making library reports at SMA Nusantara 1 Tangerang can be carried out effectively and efficiently, the development of a system for borrowing and writing books at SMU Nusantara 1 Tangerang can be done effectively and efficiently, because it is one of the system methods aimed at providing much faster development and getting better quality results. The author uses RAD in addition to aiming to shorten the time usually required in the traditional system development life cycle between the design and implementation of an information system.
\end{abstract}

Keywords: Library, borrowing, climax, RAD

\section{Pendahuluan}

Perpustakaan menjadi wahana fundamental bagi

proses pembelajaran. Pada saat pembelajaran

kosong karena guru rapat atau berhalangan

hadir, siswa dapat memanfaatkan perpustakaan sekolah sebagai wahana belajar, tentu saja diawali dengan membaca. Melalaui pemanfaatan perpustakaan ini diharapkan sekolah akan memberikan sumbangan yang sangat berharga dalam upaya peningkatan aktivitas siswa 
disamping kualitas pendidikan dan pembelajaran yang dihasilkan dan menjadikan siswa untuk senantiasa terbiasa dengan aktivitas membaca, memahami pelajaran, mengerti maksud dari sebuah informasi dan ilmu pengetahuan, sehingga menghasilkan karya bermutu. Sehingga pada akhirnya prestasipun relatif mudah untuk diraih[1]. Membaca sangat penting untuk menunjang keberhasilan tujuan pendidikan serta merupakan hal pokok yang harus menjadi kebiasaan sehari-hari. Seperti halnya telah disebutkan dalam Undang-undang No 20 Tahun 2003 tentang Sistem Pendidikan Nasional BAB III pasal 4 ayat 5 bahwa, "Pendidikan diselenggarakan dengan mengembangkan budaya membaca, menulis, dan berhitung bagi segenap warga masyarakat". Membaca merupakan kegiatan yang teramat penting dengan begitu besar manfaat yang akan didapat[2].

Permasalahan yang terjadi pada Perpustakaan SMA Nusantara 1 Tangerang adalah: 1). Sistem peminjaman dan pengembalian buku di perpustakaan SMA Nusantara 1 Tangerang masih bersifat manual. 2). Sering terjadinya kehilangan data dari hasil catatan peminjaman buku. 3). Banyaknya buku yang dipinjam namun terlambat pengembaliannya. penerapan sistem peminjaman dan pengembalian di perpustakaan SMA Nusantara 1 Tangerang dalam pengolahan datanya masih dilakukan secara manual, dimana proses pengolahan data anggota, data buku, transaksi peminjaman dan pengembalian, serta pembuatan laporan masih dicatat ke dalam buku besar dan saat mencari data yang dibutuhkan harus membuka kembali catatan tersebut. Hal ini tentu sangat tidak efektif dan akan menimbulkan kesalahan dalam proses pencatatan yang menyebabkan ketidakakuratan data, selain itu data yang dicatat pada kertas bisa sewaktuwaktu rusak atau hilang. Untuk memenuhi pelayanan yang baik dan efisien dalam aktivitas peminjaman dan pengembalian buku pada perpustakaan SMA Nusantara 1 Tangerang maka diperlukan sebuah sistem pengolahan data yang terkomputerisasi.

Tujuan dari Penelitian ini adalah Untuk mengetahui bagaimana sistem peminjaman dan pengembalian buku yang sedang berjalan di perpustakaan SMA Nusantara 1 Tangerang, Merancang program peminjaman dan pengembalian buku pada SMA Nusantara 1 Tangerang agar menghasilkan informasi yang cepat, tepat dan akurat, Agar hasil penelitian dapat dimanfaatkan dan digunakan oleh SMA Nusantara 1 Tangerang sebagai referensi dasar untuk mengambil solusi dari permasalahan yang ada, untuk mencapai tujuannya maka perpustakaan Sekolah harus memenuhi fungsi pendidikan, penelitian, informasi, rekreasi dan pelestarian. Perpustakaan Sekolah tidak hanya berfungsi untuk memenuhi kebutuhan informasi 
seluruh lingkup SMA Nusantara 1 tersebut berada, akan tetapi juga masyarakat umum dan Sekolah lainnya. Dengan menjalankan perpustakaan sesuai dengan fungsinya, maka perpustakaan juga ikut menjaga eksistensi perpustakaan di masyarakat sehingga keberadaannya semakin diakui. Data peminjaman buku semakin lama semakin banyak yang tidak dimanfaatkan dengan baik dan pengunjung sering merasa kesulitan dalam mencari beberapa buku yang saling berkaitan, memerlukan waktu yang lama karena letak buku tersebut diletakkan terpisah. Bagi staf perpustakaan sendiri merasa kesulitan dalam meletakkan buku-buku yang dikembalikan oleh pengunjung karena staf perpustakaan hanya menguasai satu bidang saja sehingga mereka tidak mengetahui buku-buku apa saja yang mempunyai relasi antara buku satu dengan yang lainnya[3]

\section{Tinjauan Pustaka}

\subsection{Penelitian Terkait}

Menurut Nur Aini,Satrio Agung Wicaksono dan Issa Arwani pada Jurnal yang berjudul “ Pengembangan Sistem Informasi Perpustakaan Berbasis Web Menggunakan Metode Rapid Application Development (RAD) (Studi pada:SMK Negri 11 Malang)" di dapat kesimpulan Perancangan pada workshop desain melibatkan pengguna, yang menghasilkan desain sistem pada iterasi pertama terdiri dari menu sekolah, jurusan, kelas, siswa, guru/staff, anggota, transaksi, buku, dan juga denda. Pada admin dapat mengakses semua fungsi sistem yang meliputi melihat data, menambah, mengedit, menghapus, mengeksport, dan merekap data[4]

Menurut Reza Trimahardika dan Entin Sutinah pada Jurnal yang berjudul "Penggunaan Metode Rapid Application Development Dalam Perancangan Sistem Informasi Perpustakaan"menyimpulkan Dengan menggunakan metode $R A D$, pengerjaan dalam pembuatan system informasi perpustakaan berbasis web ini menjadi lebih cepat dan tentunya memiliki kualitas dalam memenuhi kebutuhan pengguna tersebut. Metode RAD membuat batasan-batasan dalam pembuatan sistem sehingga sistem yang dibuat tidak keluar dari kebutuhannya. Penyelesaian setiap modul sistem perpustakaan merujuk kepada semua tahapan dari metode RAD dan semuanya dapat berjalan dengan lacar. Sistem dapat mempermudah pekerjaan petugas perpustakaan dalam mengelola data perpustakaan[5].

Menurut Dicky Hariyanto,Ricki Sastra dan Ferina Eka Putri pada Jurnal yang berjudul" Implementasi Metode Rapid Application Development Pada Sistem Informasi Perpustakaan" Metode RAD sangat cocok untuk digunakan pada sistem yang tidak begitu besar 
dan komplek peranan teknologi informasi dan komunikasi menjadi bagian yang sangat penting pada proses bisnis di semua bidang, khususnya pendidikan.Sistem informasi perpustakaan ini merupakan problems solving untuk memperbaiki proses bisnis di perpustakaan[6]

Menurut Mika Mandasari pada jurnal yang berjudul" Perancangan Sistem Informasi Perpustakaan Berbasis Web Dengan Metode Rapid Application Development (Rad) Dan Framework Css Bootstrap"di dapat kesimpulan Sistem yang dirancang menggunakan metode rapid application development dengan melalui 3 siklus yaitu requirments palnning (perencanaan syarat-syarat), design worshop, dan implementation cukup mempercepat proses pembuatan sistem ini[7].

Menurut Restu Panji Amarta dan Budiman pada jurnal yang berjudul" Pengembangan Sistem Informasi Perpustakaan Berbasis Qr Code (Quick Response Code) (Studi Kasus Perpustakaan Fakultas Teknik Universitas Majalengka)" menyimpulkan Perpustakaan Fakultas Teknik Universitas Majalengka sudah menggunakan sistem informasi mulai dari pengolahan data anggota, pengolahan data buku , peminjaman buku dan pengembalian buku,dan lain-lain. Namun sistem informasi perpustakaan ini masih terdapat kelemahan pada saat peminjaman dan pengembalian buku dimana admin harus menginputkan kembali data peminjaman buku dan pengembalian buku, sehingga membutuhkan proses yang cukup lama, terlebih lagi jika terjadi antrian pada saat peminjaman dan pengembalian buku Sehingga penulis bermaksud untuk mengembangkan sistem tersebut dengan menggunakan $Q R$ code dalam peminjaman buku agar dapat memaksimalkan waktu pada saat mahasiswa melakukan peminjaman[8]

\subsection{Landasan Teori}

1. Perpustakaan sekolah adalah perpustakaan yang berada pada lembaga pendidikan sekolah, yang merupakan bagian integral dari sekolah yang bersangkutan, dan merupakan sumber belajar untuk mendukung tercapainya tujuan pendidikan sekolah yang bersangkutan[9].

2. Rapid Application Development (RAD) merupakan salah satu metode pengembangan aplikasi yang menekankan pada siklus perkembangan dalam waktu yang singkat[10]. Menurut Jijon Waktu yang singkat adalah batasan yang penting untuk model ini. Rapid Application Development (RAD) menggunakan metode iterative (berulang) dalam mengembangkan sistem dimana working model (model kerja) sistem dikonstruksikan diawal tahap pengembangan dengan tujuan menetapkan kebutuhan (requirement) pengguna [11] 
Peminjaman Secara sederhana, pinjaman dapat diartikan sebagai barang atau jasa yang menjadi kewajiban pihak yang satu untuk dibayarkan kepada pihak lain sesuai dengan perjanjian tertulis ataupun lisan, yang dinyatakan atau diimplikasikan serta wajib dibayarkan kembali dalam jangka waktu tertentu[12]

\subsection{Tahapan Penelitian}

Metodologi RAD berikut ini adalah tahap-tahap pengembangan aplikasi dari tiap-tiap fase pengembangan aplikasi dapat di lihat pada gambar 1.



Gambar 1. Model Rapid Application

Development (RAD)

Dalam model ini ada beberapa tahapan pengembangan sistem Rapid Application Development yaitu:

1. Rencana Kebutuhan (Requirement Planning) Fase antara penganalisis dan pengguna untuk mengidentifikasikan tujuan dari sistem yang akan dibangun serta mengidentifikasikan syarat-syarat informasi yang akan timbul untuk mencapai tujuan tersebut serta menganalisa semua sistem yang dibutuhkan oleh pengguna[14]

2. Desain Pengguna (User Design)

Tahap membuat rancangan yang akan diusulkan agar sesuai dengan kebutuhan, berjalan sesuai rencana dan diharapkan dapat mengatasi masalah yang sedang terjadi. Pada penelitian ini, desain sistem yang digambarkan menggunakan Tools Unified Modeling Language (UML)[[13]

3. Konstruksi (Construction)

Fase eksekusi dalam bentuk pembuatan script program dan merupakan kelanjutan dari fase kedua. Menunjukkan platform, hardware dan software yang digunakan.Setiap desain yang dibuat pada fase sebelumnya akan ditingkatkan dengan menggunakan perangkat $R A D$. Setelah fungsi baru tersedia, fungsi baru tersebut ditunjukkan kepada pengguna untuk mendapatkan interaksi dan revisi, selanjutnya penganalisis akan melakukan perubahan dalam setiap desain aplikasi berdasarkan instruksi dari pengguna[14]

\section{Cutover}

Tahap ini adalah pengujian keseluruhan sistem yang dibangun semua komponen perlu diuji secara menyeluruh dengan Black Box Testing supaya dapat mengurangi risiko cacat sistem. Black-Box Testing merupakan teknik pengujian perangkat lunak yang berfokus pada spesifikasi fungsional dari perangkat lunak[15]

\section{Metode Penelitian}

\subsection{Metodelogi Penelitian}

Penelitian ini Penulis menggunakan menggunakan metode pengumpulan data dengan observasi dan wawancara kepada 
pemilik usaha yang selanjutnya dianalisis untuk mengetahui kelayakan dan model bisnis dari aplikasi. Untuk pengembangan perangkat lunak kami menggunakan Rapid Application Development pada SMA Nusantara 1 karena tahapan-tahapannya terstruktur,pengembangan perangkat lunak dapat dilakukan dalam waktu yang cepat dengan menekankan pada siklus yang pendek, software yang dikembangkan dapat diketahui hasilnya tanpa menunggu waktu yang lama dengan metode pengembangan ini akan bekerja dengan baik jika diterapkan pada aplikasi yang berskala kecil.

Rapid Application Development adalah suatu pendekatan berorientasi objek terhadap pengembangan sistem yang mencakup suatu metode pengembangan serta perangkat perangkat lunak. Rapid Application Development bertujuan mempersingkat waktu yang biasanya diperlukan dalam siklus hidup pengembangan sistem tradisional antara perancangan dan penerapan suatu sistem informasi[16]

\subsection{Lokasi Penelitian}

SMA Nusantara 1Tangerang berlokasi di Jl. Cisadane VII Perumnas 1 Tangerang. SMA NUSANTARA 1 didirikan tahun 1981 dan mulai melaksanakan fungsinya sebagai lembaga pendidikan pada tahun pelajaran 1981/1982 dengan SK Pendirian Sekolah No. 152/102.Kep/E81 tanggal 13 Juli 1981. SMA
Nusantara 1 bernaung dibawah pengelolaan Yayasan Pendidikan Abdi Negara (YPAN) dengan dewan pendiri oleh Alm. Bpk. H. Adih Suganda. Kemudian pada tahun 1986 SMA Nusantara berdiri sendiri.

\section{Hasil dan Pembahasan}

Menguraikan gambaran mengenai prosedur dari sistem yang terdapat di dalam program. Berikut tahapan-tahapan analisis kebutuhan yang penulis lakukan untuk merancang sistem peminjaman dan pengembalian buku pada perpustakaan.

\subsection{Kebutuhan Sistem Dan Program}

Adapun kebutuhan sistem yang digunakan adalah sebagai berikut:

a. Untuk dapat masuk ke dalam menu utama, petugas harus login terlebih dahulu dengan cara memasukkan id petugas dan password dengan benar.

b. Admin dapat mengakses dan mengelola semua form yang terdapat dalam sistem peminjaman dan pengembalian buku. Sedangkan user hanya dapat mengakses login, lupa password, data master (data anggota, buku, kategori), data transaksi (data peminjaman dan data pengembalian), laporan (laporan data buku, peminjaman dan pengembalian), ganti password, dan logout saja. 
c. Di dalam sistem peminjaman dan pengembalian buku dibutuhkan beberapa menu yaitu menu master (data petugas, anggota, buku, dan kategori), menu transaksi (data transaksi peminjaman dan data transaksi pengembalian), laporan (buku, transaksi peminjaman dan transaksi pengembalian), pengaturan (ganti password) dan logout.

d. Petugas harus logout setelah menggunakan sistem aplikasi peminjaman dan pengembalian buku.

\subsection{Rancangan Sistem dan Program}

Dalam sistem peminjaman dan pengembalian buku ini terdapat dua petugas yaitu admin dan user yang memiliki hak akses masing-masing berbeda diantaranya:

\section{Admin}

- Dapat melakukan login ke dalam program aplikasi peminjaman dan pengembalian buku.

- Dapat mengakses lupa password.

- Dapat menambah, mengubah dan menghapus data petugas.

- Dapat menambah, mengubah, dan menghapus data anggota.

- Dapat menambah, mengubah, dan menghapus data buku.

- Dapat menambah, mengubah, dan menghapus data kategori.
- Dapat menambah data transaksi peminjaman.

- Dapat menambah data transaksi pengembalian.

- Dapat melihat dan mencetak laporan buku, transaksi peminjaman dan transaksi pengembalian.

- Dapat mengganti password.

- Dapat logout dari program aplikasi peminjaman dan pengembalian buku.

2. User

- Dapat melakukan login ke dalam program aplikasi peminjaman dan pengembalian buku.

- Dapat mengakses lupa password.

- Dapat menambah, mengubah, dan menghapus data anggota.

- Dapat menambah, mengubah, dan menghapus data buku.

- Dapat menambah, mengubah, dan menghapus data kategori.

- Dapat menambah data transaksi peminjaman.

- Dapat menambah data transaksi pengembalian.

- Dapat melihat dan mencetak laporan buku, transaksi peminjaman dan transaksi pengembalian.

- Dapat mengganti password.

- Dapat logout dari program aplikasi peminjaman dan pengembalian buku. 


\subsection{Entity Relationship Diagram (ERD)}

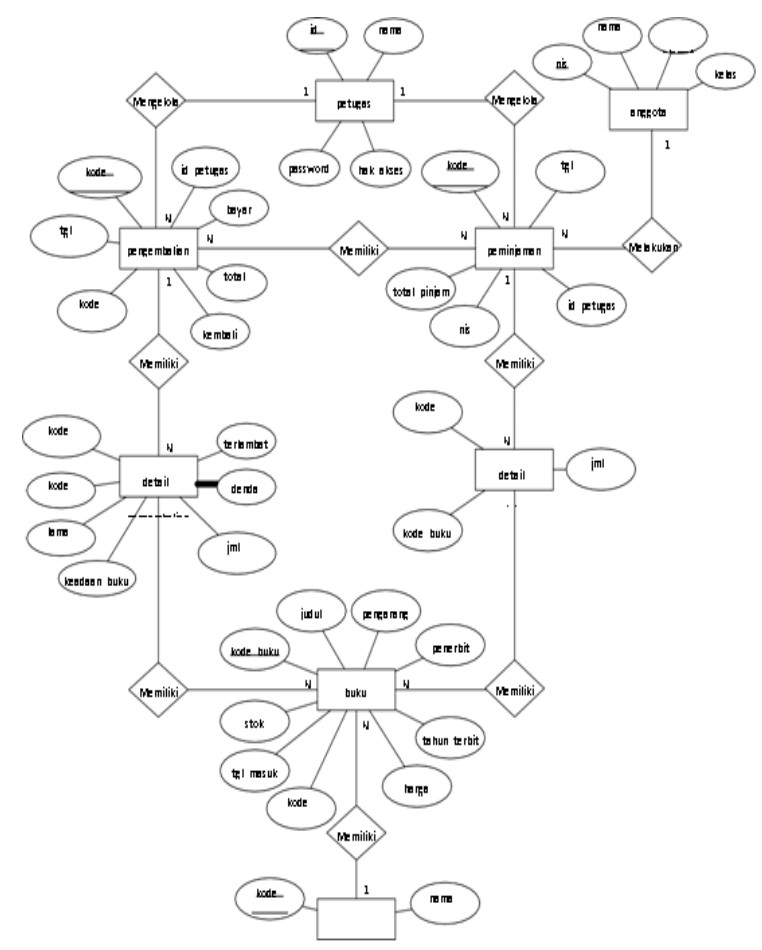

Gambar 2. ERD Peminjaman dan Pengembalian Buku

Setelah menggambarkan ER-Diagram, selanjutnya kita akan mentransfomasi ERDiagram tersebut ke Logical Record Structure (LRS). Aturan-aturan yang berlaku untuk mentransformasikan ER-Digram ke LRS.

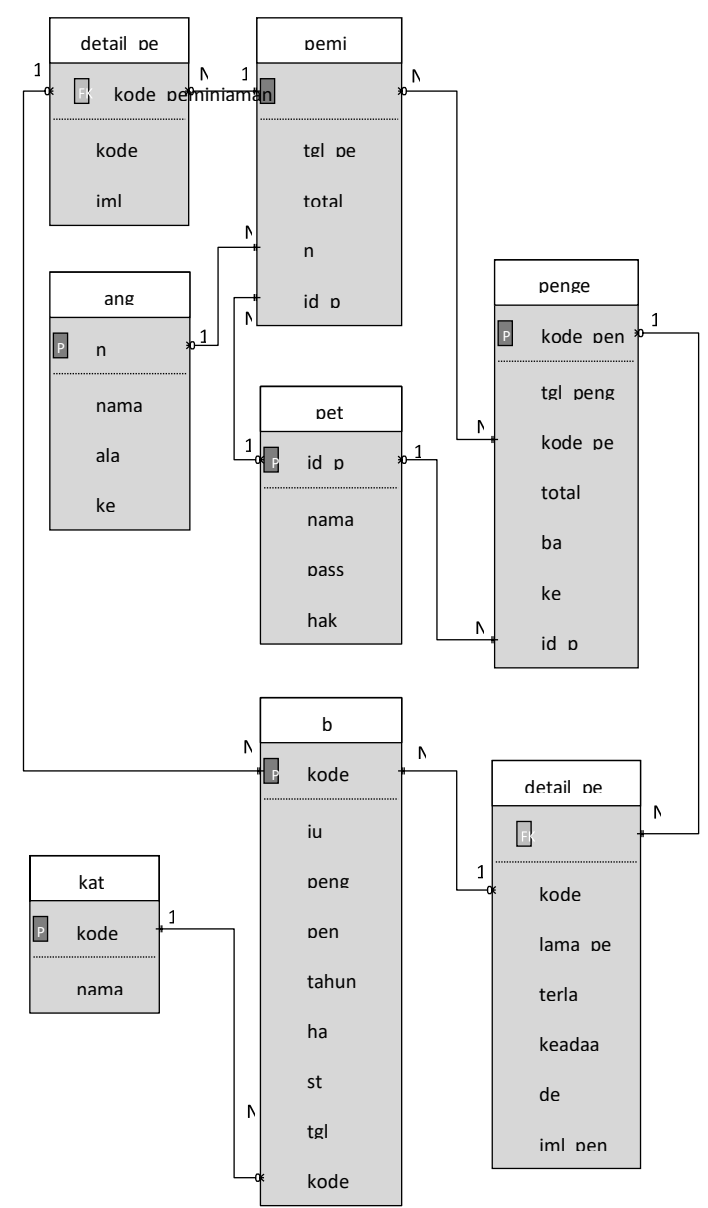

Gambar 3 LRS (Logical Record Structure)

\section{Halaman Login}

Petugas atau admin harus melakukan login di halaman ini agar bisa masuk ke menu utama.

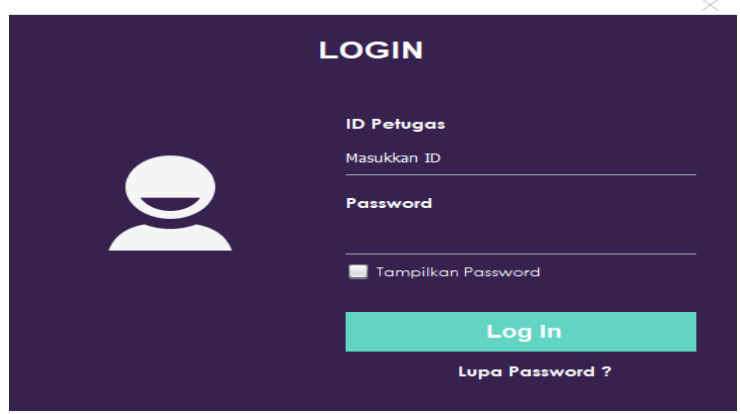

Gambar 3.3 Halaman Login 


\section{Halaman Lupa Password}

Petugas yang mengalami lupa password dapat mengakses halaman ini agar bisa login untuk masuk ke menu utama

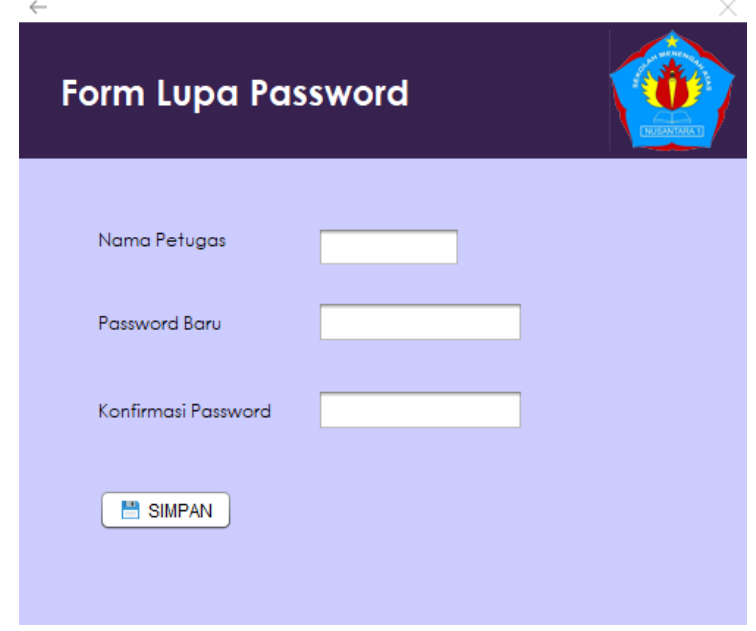

Gambar 3.4 Halaman Lupa Password

\section{Halaman Menu Utama Admin}

Setelah petugas berhasil memasukan id petugas dan password, muncul halaman utama dari aplikasi. Dalam halaman utama terdapat menu yang dapat dioperasikan oleh admin. Admin dapat mengoperasikan semua menu yang ada didalam aplikasi.

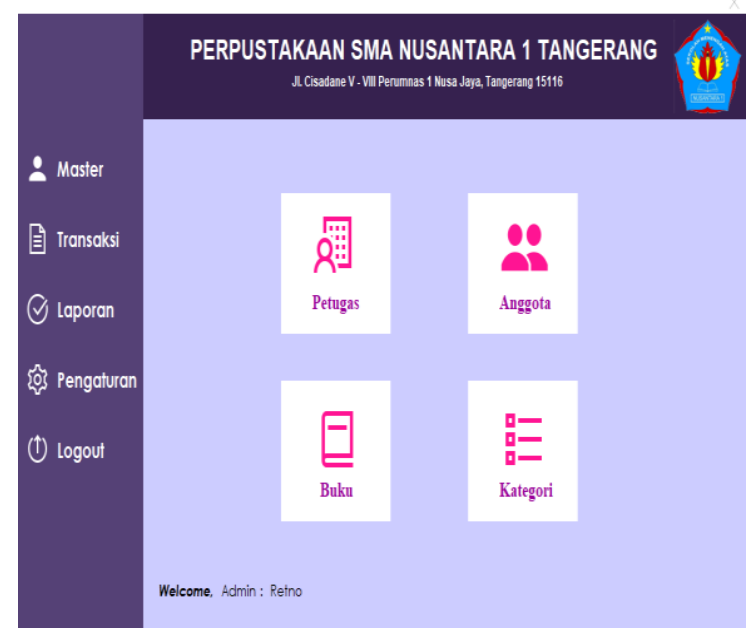

4. Halaman Menu Utama User

Pada halaman menu user, menu petugas tidak dapat diakses, berbeda dengan admin yang dapat mengelola semua form pada aplikasi.

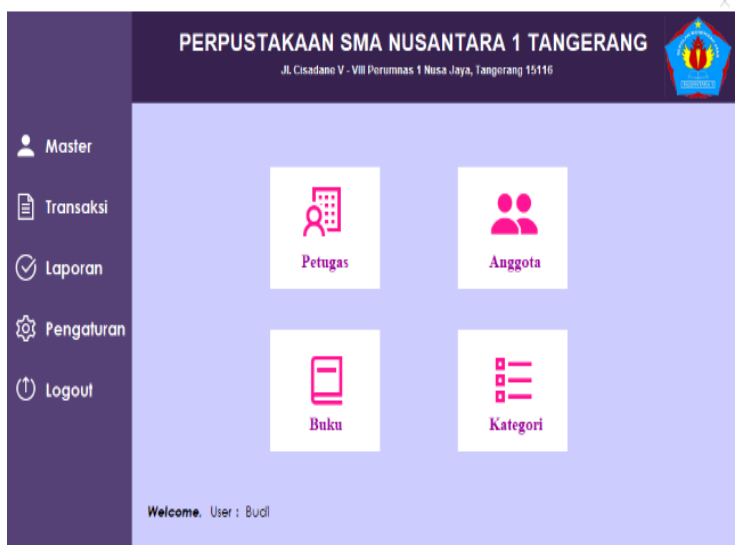

Gambar 3.6 Halaman Menu Utama User

5. Halaman Form Petugas

Admin pada halaman ini dapat memasukan data petugas baru, edit, dan menghapus data petugas.

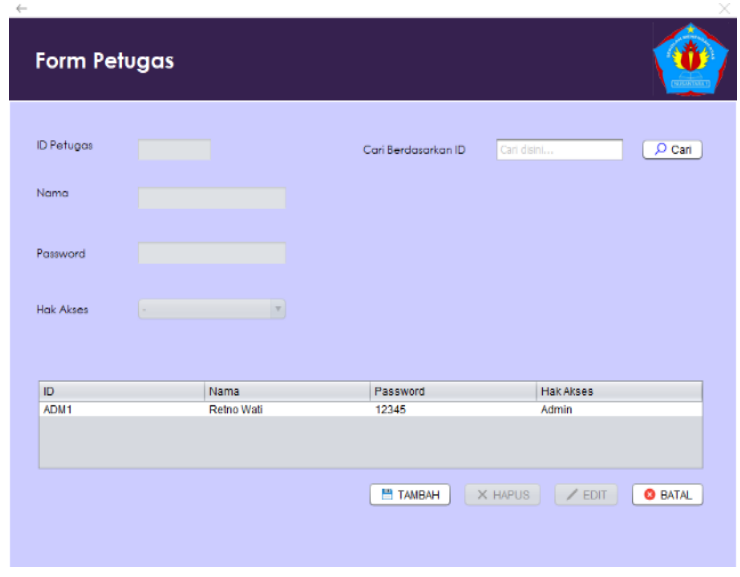

Gambar 3.7 Halaman Form Petugas

6. Halaman Form Anggota

Admin atau user pada halaman ini dapat memasukan data anggota baru, edit, dan menghapus data anggota.

Gambar 3.5 Halaman Menu Utama Admin 




Gambar 3.8 Halaman Form Anggota

\section{Halaman Form Buku}

Admin atau user pada halaman ini dapat memasukan data buku baru, edit, dan menghapus data buku.

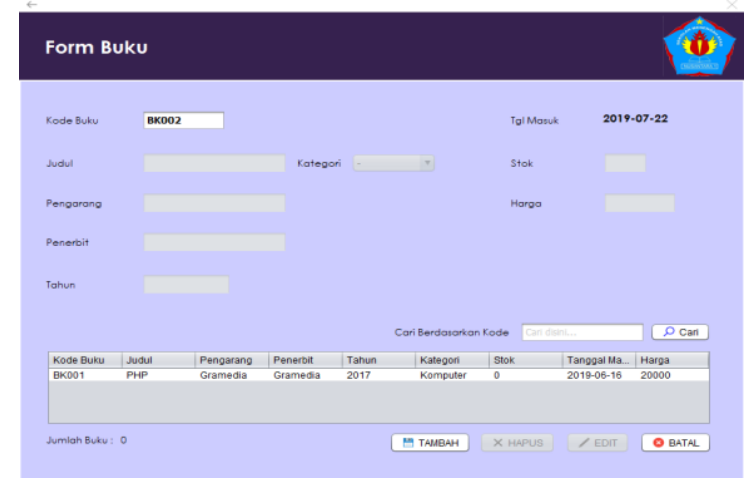

Gambar 3.9 Halaman Form Buku

\section{Halaman Form Kategori}

Admin atau user pada halaman ini dapat memasukan data kategori baru, edit, dan menghapus data kategori.

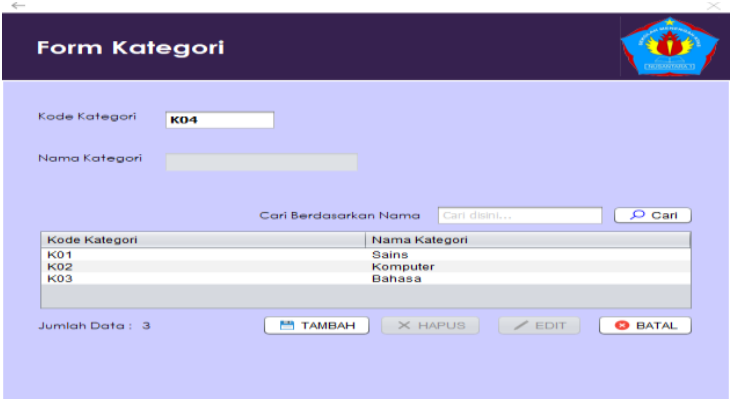

Gambar 3.10 Halaman Form Kategori
9. Halaman Form Peminjaman

Admin atau user pada halaman ini dapat melakukan transaksi peminjaman buku kepada anggota yang akan meminjam buku.

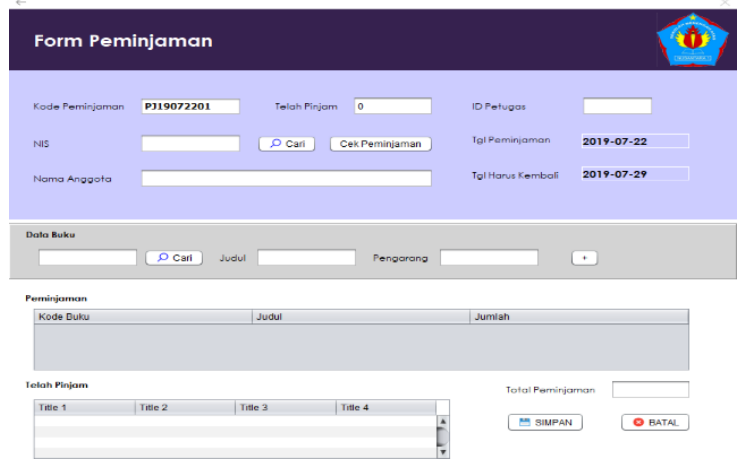

Gambar 3.11 Halaman Form Peminjaman

10. Halaman Form Pengembalian

Admin atau user pada halaman ini dapat melakukan transaksi pengembalian buku kepada anggota yang akan mengembalikan buku.

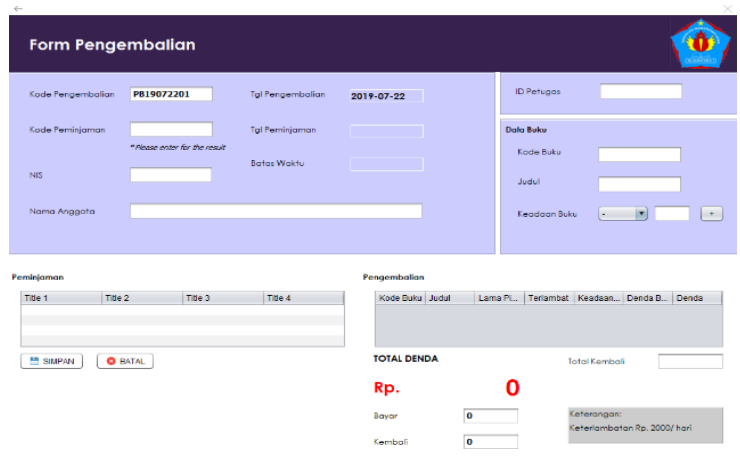

Gambar 3.12 Halaman Form Pengembalian

11. Halaman Laporan Buku

Admin atau user pada halaman ini dapat menampilkan laporan buku secara per periode atau per bulan. 


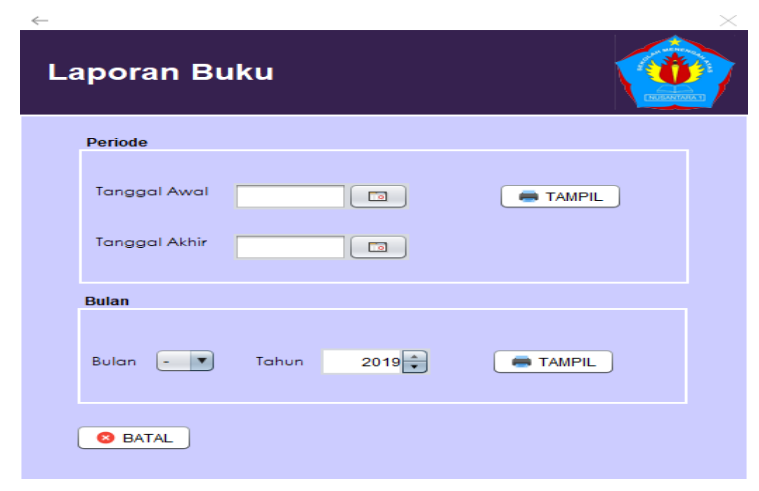

Gambar 3.13 Halaman Laporan Buku

12. Halaman Laporan Peminjaman

Admin atau user pada halaman ini dapat menampilkan laporan peminjaman secara harian atau per periode atau per bulan.

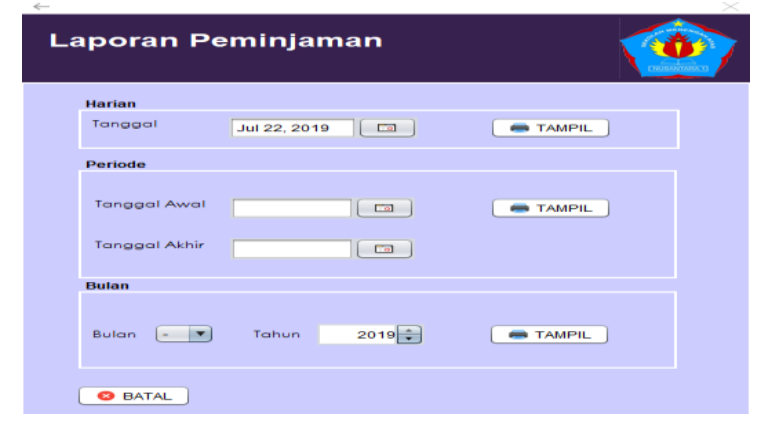

Gambar 3.14 Halaman Laporan Peminjaman

\section{Halaman Ganti Password}

Admin atau user pada halaman ini dapat mengganti password masing-masing.

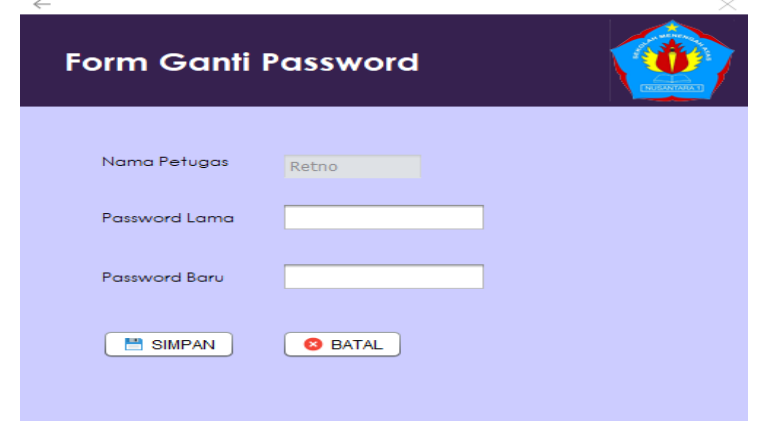

Gambar 3.15 Halaman Ganti Password

\section{Kesimpulan}

Berdasarkan hasil penelitian yang telah dilakukan maka dapat diambil beberapa kesimpulan, yaitu:

a. Sistem komputerisasi dapat menjadi alternatif dalam proses pengolahan data peminjaman dan pengembalian buku pada perpustakaan SMA Nusantara 1Tangerang.

b. Mengurangi kesalahan yang terjadi ketika proses peminjaman, pengembalian buku serta pembuatan laporan pada perpustakaan SMA Nusantara 1 Tangerang

c. Mempermudah dalam proses peminjaman dan pengembalian buku serta pembuatan laporan.

d. Keamanan lebih terjamin karena tidak semua bisa mengakses program.

\section{Daftar Pustaka}

[1] A. Akbar, W. O. D. Aplisalita, and L. O. Rusadi, "Fungsi Perpustakaan Sekolah Terhadap Prestasi Belajar Siswa Sekolah Dasar," Edukatif : Jurnal Ilmu Pendidikan, vol. 3, no. 1, pp. 203-212, 2021, doi: 10.31004/edukatif.v3i1.286.

[2] I. Syarif and E. Elihami, "Pengadaan Taman Baca Dan Perpustakaan Keliling Sebagai Solusi Cerdas Dalam Meningkatkan Minat Baca Peserta Didik," Maspul Journal of Community Empowerment, vol. 1, no. 1, pp. 109-117, 2020.

[3] Sastie, Dessi Eka, Suparni and A. B. Pohan, "Analisa Algoritma Apriori Pada Pola Peminjaman Buku di," vol. 4, pp. 136-143, 2020, doi: $10.30865 / m i b . v 4 i 1.1475$.

[4] N. Aini, S. A. Wicaksono, and I. Arwani, "Pembangunan Sistem Informasi 
Perpustakaan Berbasis Web menggunakan Metode Rapid Application Development (RAD) (Studi pada: SMK Negeri 11 Malang)," 2019. [Online]. Available: http://jptiik.ub.ac.id

[5] R. Trimahardhika and E. Sutinah, "249 260 Diterima Agustus 14," JURNAL INFORMATIKA, vol. 4, no. 2, 2017.

[6] D. Hariyanto, R. Sastra, F. E. Putri, S. Informasi, K. Kota Bogor, and T. Komputer, "Implementasi Metode Rapid Application Development Pada Sistem Informasi Perpustakaan," 2021.

[7] M. Mandasari, "Perancangan Sistem Informasi Perpustakaan Berbasis Web Dengan Metode Rapid Application Development (Rad) Dan Framework Css Bootstrap," Poliprofesi, 2021.

[8] R. Panji Amarta, "Pengembangan Sistem Informasi Perpustakaan Berbasis Qr Code (Quick Response Code) (Studi Kasus Perpustakaan Fakultas Teknik Universitas Majalengka)," 2021.

[9] T. Anjani, Z. Niswati, and I. Mutia, "Perancangan Aplikasi Peminjaman Buku Perpustakaan Pada SDN Mekarjaya 11 Depok," STRING (Satuan Tulisan Riset dan Inovasi Teknologi), vol. 5, no. 1, p. 101, 2020, doi: $10.30998 /$ string.v5i1.4883.

[10] A. Adhityarahman, L. Andrawina, and R. P. Soesanto, "Rancangan Management Information System Pada Kegiatan Praktikum Di Laboratorium Program Studi S1 Teknik Industri Dengan Metode Rapid Application Development," vol. 8, no. February, pp. 1-27, 2021.

[11] J. R. Sagala, "Model Rapid Application Development (Rad) Dalam Pengembangan Sistem Informasi Penjadwalan Belajar Mengajar," Jurnal Mantik Penusa, vol. 2, no.
1, pp. 87-90, 2018.

[12] Y. Pratama, L. P. Dewi, and A. Setiawan, "Sistem Informasi Simpan Pinjam Koperasi Citra Abadi," 2021. [Online]. Available: http://publication.petra.ac.id/index.php/tekni k-informatika/article/viewFile/10671/9499

[13] Kissflow, "Rapid Application Development (RAD): Changing How Developers Work," kissflow.com, 2021. https://kissflow.com/low-code/rad/rapidapplication-development/ (accessed Jun. 13, 2021).

[14] M. Badrul and N. S. Dewi, "Penerapan Metode Rapid Application Development untuk Perancangan Sistem Informasi Penagihan Piutang Premi Asuransi," vol. 4, no. September, pp. 319-326, 2020.

[15] N. Hidayat and K. Hati, "Penerapan Metode Rapid Application Development ( RAD ) dalam Rancang Bangun Sistem Informasi Rapor Online ( SIRALINE )," no. 1, pp. 817, 2021.

[16] P. Rahman Abdul, "Penerapan Metode Rapid Application Development (Rad) Dalam Pengembangan Sistem Aplikasi Maintenance Di Pt Multistrada Arah Sarada Tbk Berbasis Mobile," vol. 5, no. 2, pp. 2432, 2020.

[17] S. Aswati, M. S. Ramadhan, A. U. Firmansyah, and K. Anwar, "Studi Analisis Model Rapid Application Development Dalam Pengembangan Sistem Informasi," Jurnal Matrik, vol. 16, no. 2, p. 20, 2017, doi: $10.30812 /$ matrik.v16i2.10.

[18] A. Sudianto, Nurhidayati, and L. Wijaya, Kerta, "Penerapan Sistem Informasi Geografis Untuk Pemetaan Bengkel Tambal Ban di Kecamatan Selong Kabupaten Lombok Timur," Infotek J. Inform. dan Teknol., vol. 3, no. 1, pp. 51-57, 2020. 